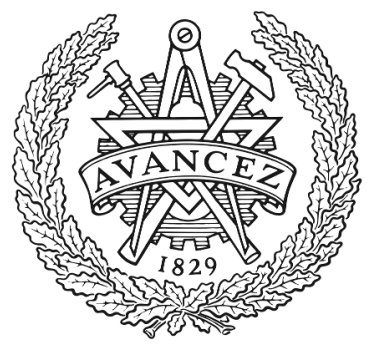

CHALMERS

UNIVERSITY OF TECHNOLOGY

\title{
Effects of biodiversity and environment-related attitude on perception of urban green space
}

Downloaded from: https://research.chalmers.se, 2023-04-26 14:38 UTC

Citation for the original published paper (version of record):

Gunnarsson, B., Knez, I., Hedblom, M. et al (2017). Effects of biodiversity and environment-related attitude on perception of urban green space. Urban Ecosystems, 20(1): 37-49.

http://dx.doi.org/10.1007/s11252-016-0581-x

N.B. When citing this work, cite the original published paper. 


\title{
Effects of biodiversity and environment-related attitude on perception of urban green space
}

\author{
B. Gunnarsson ${ }^{1}$ (D) - I. $\mathrm{Knez}^{2} \cdot$ M. Hedblom ${ }^{3}$ Å. Ode Sang ${ }^{4}$
}

Published online: 14 July 2016

(C) The Author(s) 2016. This article is published with open access at Springerlink.com

\begin{abstract}
Green space in cities contributes to the quality of life for city dwellers, e.g., by increasing the opportunity for recreation. However, perception of urban green space is influenced by multiple factors. We investigated effects of biodiversity and environment-related attitudes on visual and auditory perceptions of urban green space. Field measurements of biodiversity were conducted in six sites across an urban gradient in Gothenburg, Sweden, and three categories of biodiversity-high, medium, low-were established. Households were sent a survey on aesthetic perception of urban green space, sound perception and the importance of trees and plants for the perception of bird species. Each respondent focused on the site that was located nearby. The environment-related attitudes comprised "Nature-oriented" and "Urban-oriented" persons and were based on participants' own attitude estimations. It was shown that participants' "subjective" aesthetic and sound-related perception of urban greenery were in line with the "objectively" measured subdivisions of high, medium and low biodiversity. So also were their estimations of the importance of trees and plants for perception of bird species in urban
\end{abstract}

B. Gunnarsson

bengt.gunnarsson@bioenv.gu.se

1 Department of Biological and Environmental Sciences, University of Gothenburg, Box 461, SE 40530 Göteborg, Sweden

2 Department of Social Work and Psychology, University of Gävle, SE 80176 Gävle, Sweden

3 Department of Forest Resource Management, c/o Department of Ecology, Swedish University of Agricultural Sciences, Box 7044, SE 75007 Uppsala, Sweden

4 Department of Landscape Architecture, Planning and Management, Swedish University of Agricultural Sciences, Box 66, SE 230 53 Alnarp, Sweden greenery, although differing only between high and medium/ low biodiversity conditions. Persons rating themselves as highly nature-oriented were shown to give higher scores to urban green space aesthetics and to value greenery-related sounds higher, and to attach greater importance to trees and plants in their perception of bird species in urban greenery, than less nature-oriented persons. Highly urban-oriented persons compared to less urban-oriented persons did the same, but only regarding urban greenery-related aesthetics and sounds of nature. We conclude that environment-related attitudes influence perceptions of green space. Moreover, our findings support the idea that biodiversity per se also influences perceptions; people value green space significantly more with high than with low measured biodiversity. Urban planning needs to provide city inhabitants with green spaces that are species-rich, lush, varied and rich with natural sounds.

Keywords Aesthetic perception · Bird song · Soundscape · Species richness $\cdot$ Urban vegetation

\section{Introduction}

The global urbanization process has led to a rapid transformation of various urban and suburban habitats with profound consequences for biodiversity (e.g. McKinney 2006; Seto et al. 2012). Improving the conditions for biodiversity in cities has been suggested to contribute to quality of life for city dwellers (e.g. Tzoulas et al. 2007; Standish et al. 2012). For instance, human well-being in cities has been attributed to, among other factors, access to green space with variety in the form of species-rich habitats (e.g. Fuller et al. 2007; Dallimer et al. 2012). One important aspect of the presence of various organisms in urban areas is the opportunity for people to experience plants and animals for recreational 
purposes. This can be viewed as part of the ecosystem services in cities, i.e. the various benefits that humans receive from ecosystems including urban ones (MEA 2005; Clark et al. 2014). For many urban inhabitants, the everyday experience of biodiversity is gained by visiting a nearby green space in the city.However, there are still a number of less well-known links between people and biodiversity in urban green space. A focal question is how green space is perceived. We focus here on (1) the possible "mismatch" between variation in urban biodiversity and how it is perceived (e.g. Dallimer et al. 2012); (2) the importance of environment-related attitudes of different individuals for perception of green space (e.g. Lin et al. 2014); (3) how the natural sounds in urban green space are perceived in relation to biodiversity and environmentrelated attitudes (e.g. Viollon et al. 2002; Irvine et al. 2009). These approaches were employed because our previous studies have shown that environment-related attitudes and natural sounds influence perception (Knez and Thorsson 2006, 2008; Hedblom et al. 2014). Here we investigate the effects of, and interactions between, these factors regarding perception of urban green space. Below, we describe the concerns that are related to the three approaches.

First, the relationship between actual and perceived biodiversity may not be so straightforward as might be expected (e.g. Fuller et al. 2007). Several studies have recently focused on this problem (Dallimer et al. 2012; Shwartz et al. 2014; Pett et al. 2016). For instance, in a study in England, it was shown that the well-being of visitors to green space was positively related to the perceived species richness of plants, birds and butterflies. But no consistent pattern was found between actual, measured species richness and the well-being of participants in the study (Dallimer et al. 2012). In other studies, the vegetation has been in focus because it is usually a major part of the perceived urban biodiversity. When flower diversity was experimentally increased in small public gardens in Paris, the visitors did not perceive any change in diversity before and after the manipulation although the participants expressed a preference for species richness (Shwartz et al. 2014). In another experimental study, Lindemann-Matthies et al. (2010) found that lay people appreciated species-rich, high-diversity grass communities more than species-poor ones. However, their study was performed on a rather small scale. Fuller et al. (2007) investigated green space in Sheffield and showed that visitors' "reflection" and "distinct identity" were positively related to plant species richness. Other studies have indicated that urban areas with a high level of both plant and animal biodiversity contribute to the well-being, or positive emotions, of city inhabitants (e.g. Luck et al. 2011; Hedblom et al. 2014; Carrus et al. 2015) but it is unknown whether the participants based their judgements on actual biodiversity. Thus, there is uncertainty about the congruence between "objectively" measured and "subjectively" perceived biodiversity in urban green space. This might have implications for management and urban planning; i.e. does a high level of biodiversity matter?

However, it can be questioned whether "high" biodiversity is encountered at all, or even preferred, in urban sites. The highest level of biodiversity might be so complex that it is difficult to grasp the number of species. For instance, in a study with three levels - high, intermediate, low — of forest vegetation biodiversity, the participants preferred the biotope with an intermediate level of biodiversity (Johansson et al. 2014). In the present paper, we use the word "high" in a relative sense by making comparisons with other levels of measured biodiversity in urban green space. The level of biodiversity was defined by multiple taxa. For instance, we measured species density of trees ("high" referring to 44-74 spp/ ha) and diversity of songbirds ("high" referring to 11 for Simpson's index (1/D)).

A second factor that should be addressed in more detail is how biodiversity is perceived by different individuals (Hartig et al. 2014; Lin et al. 2014). There are a multitude of reasons to expect large variation among individuals in perceiving an urban green space. For instance, there is evidence that individuals gain even more benefit from green space when suffering from fatigue (e.g. Hartig and Staats 2006). The level of recreational activity by different groups of visitors might influence how urban nature is perceived (e.g. Perelman et al. 2013). Moreover, other studies have shown links between major personality traits and attitudes related to environmental engagement and nature (e.g. Pettus and Giles 1987; Hirsch and Peterson 2009; Nisbet et al. 2009; Milfont and Sibley 2012) implying individual differences in perceiving urban green spaces. We focus on the problem of individual differences in perception by studying environment-related attitudes.

Attitude can be regarded as a psychological construct that has some bearing on how people learn and perceive an urbanrelated environment. An attitude can be treated as a type of schema (Eagly and Chaiken 1993), which is a set of knowledge structures and expectations stored in memory that may elicit behavioral, affective and cognitive consequences (Knez et al. 2009). Brewer and Treyens (1981) suggested that schemata might affect encoding, storing and retrieving information in the memory of physical places (Knez 2006, 2014). In line with this, Knez and Thorsson (2006; 2008) have shown that both collectivistic environmental attitudes (e.g. those imposed by cultures on their members) and individualistic ones (e.g. those of urban-oriented and nature-oriented persons) might affect persons' perceptions of urban places. Also, Knez (2005) showed that the city facilitated more everyday life and conveyed more positive feelings to urban-oriented persons than to nature-oriented persons. Accordingly, this indicates an influence of environment-related schemata stored in human long-term memory that might guide persons' different expectations and perceptions of urban-related issues and environments (Knez 2013; Knez et al. 2013). 
Third, soundscape also contributes to the total city environment and influences people's perception of urban green space. Previous studies of urban soundscape have shown that natural sounds such as breeze in tree canopies and birdsong are perceived as more pleasant than man-made sounds that dominate cities (e.g. Carles et al. 1999; Viollon et al. 2002; Irvine et al. 2009). However, few investigations have examined in detail how natural sounds are perceived. Among natural sounds in cities singing by birds has been found to enhance positive feelings and to be associated with relaxation (Björk 1986; Viollon et al. 2002; Ratcliffe et al. 2013; Hedblom et al. 2014). In fact, birdsong influenced the visual perception of urban sites in an experiment with young urban people (Hedblom et al. 2014). In another experimental study, Annerstedt et al. (2013) suggested that there is an enhanced stress recovery through sounds of nature, by comparing recovery in a virtual nature environment with and without sounds of nature. Their findings demonstrate a potential mechanistic link between nature, the sounds of nature, and stress recovery. But the influence of natural sounds on perception of urban green space is largely unknown. We investigated whether there are links between sound perception and biodiversity level and environment-related attitudes.

Given the concerns above, understanding how city inhabitants as individuals with different attitudes experience biodiversity, including both visual and auditory perceptions, is of importance to urban planning. How city inhabitants with different environment-related attitudes perceive green space, for example might influence the management regimes that are employed. We focus here on how people living in the city perceive their nearby green space. Our aim was to investigate effects of biodiversity and environment-related attitudes of "Nature-oriented" and "Urban-oriented" persons (based on participants' own attitude estimations) on aesthetic perception of urban green space, nature sounds (e.g. singing by birds) and the importance of trees and plants for the perception of bird species in urban green space, i.e. links between different aspects of biodiversity. Our hypotheses were: (1) the actual, measured biodiversity in a site will influence perceptions of that green space; (2) the subjective attitude of nature-oriented vs. urban-oriented person will influence perceptions of green space.

\section{Material and methods}

\section{Overview of study design}

We selected six urban sites with greenery across an urban gradient in Gothenburg, Sweden $\left(57^{\circ} 42^{\prime} \mathrm{N}, 11^{\circ} 58^{\prime} \mathrm{E}\right)$ (Fig. 1). The sites ranged from a residential area with lawns and mainly ornamental vegetation, to suburban woodland with predominantly natural vegetation. Thus the sites included

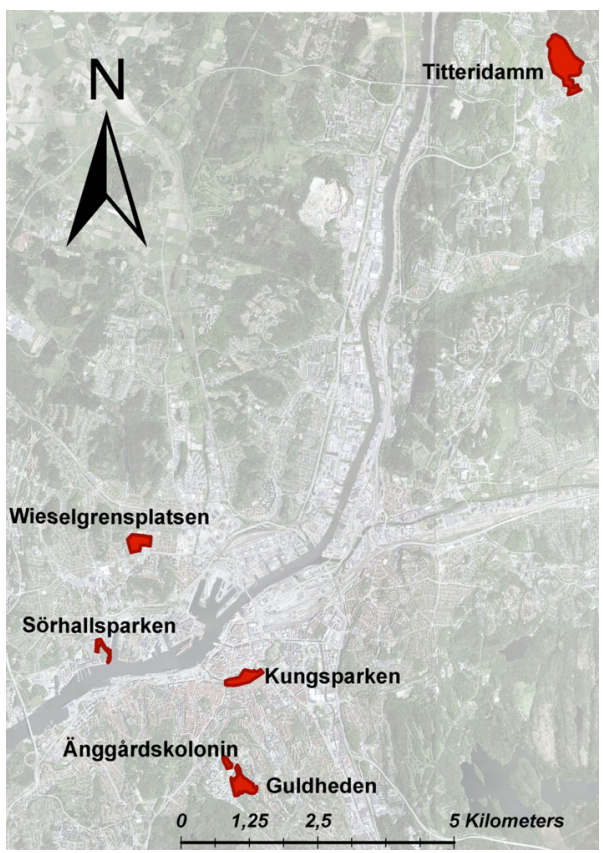

Fig. 1 Six study sites across the city of Gothenburg, Sweden

variation in type and amount of urban greenery (see details below). We measured biodiversity to assess the biological variation in each site. People living near to each site were sent a survey on, e.g., their perception of that particular site. The respondents also rated their own environment-related attitude. We analysed various perceptions (see below) in relation to (i) the measured biodiversity on each site and (ii) environmentrelated attitude.

\section{Sample}

A total of 2866 households living near the six study sites, located within the city of Gothenburg, with a population of ca. 533,000 (1 Jan 2014; see Statistics Sweden 2016), were sent a survey. People aged over 18 were included in the sample. They were randomly identified from a complete register of population ("Folkbokföringsregister"). After three contacts 1347 replies were obtained; $56.8 \%$ of them from women and $43.2 \%$ men, distributed across six age groups of $\leq 25$ (9.2\%), 26-35 (24\%), 36-45 (12.5\%), 46-55 (14.4\%), $56-65(21.4 \%)$ and $66+(18.3 \%)$. Data on aesthetic perception of urban green space, urban green-space-related sound perception and importance of trees and plants for the perception of bird species in urban green space will be reported in this study.

\section{Study sites}

Our six sites differ in type of greenery and building structure close to green space, ranging from suburban woodland to residential area. They are distributed across the city and the 
areas were selected to represent different types of green space and various levels of biodiversity along an urban gradient (Fig. 1, Table 1).

Titteridamm is a forest site on the outskirts of the city. There are residential areas with row houses and small buildings adjacent to the woodland in the south. Traffic routes surround the area in the other directions. The vegetation is a mixed forest with birch (Betula pendula, B. pubescens), pine (Pinus silvestris) and spruce (Picea abies) as the predominant tree species. The shrub layer consists of e.g. alder buckthorn (Frangula alnis) and rowan (Sorbus aucuparia). The species composition is typical of a natural forest on nutrient-poor ground in the Gothenburg area. Apart from a small area (ca $0.5 \mathrm{ha}$ ), close to the houses, with a pond and a paved walkway, the woodland is left unmanaged and without any big trails.

Guldheden is urban woodland surrounded by three-storey buildings, taller towerblocks, a University hospital and local traffic routes. The site is dominated by deciduous trees such as oak (Quercus robur), aspen (Populus tremula) and birch, and by shrubs such as rowan and hazel (Corylus avellana). This is typical woodland on nutrient-rich ground in the Gothenburg area. A few paved walkways through the area permit easy access for the public. But maintenance of the area is minimal, i.e. removal of shrubs close to the walkways.

Sörhallsparken is a newly established park (ca 10 years) with open lawns, a few small ornamental trees (Prunus sp) and groups of bushes in a formal-garden style. However, in the middle of the area, there is a rocky knoll with natural woodland. Predominant trees on the rock are oak, birch and Swedish Whitebeam (Sorbus intermedia). There are newly built residential areas with multi-storey buildings and row houses around most of the area but the southern side of the park is borded by the Göta River.

Änggårdskolonin is an old allotment area that was founded in 1913. The area is situated between a campus area (medical faculty and biology) and a residential area with three-storey buildings. There are 50 small private gardens with huts, a common green space and walkways to be used by the public. Domesticated trees and plants are predominant in the area, e.g. apple (Malus $x$ domestica), Prunus sp., black and red currant (Ribes spp), some crops and multiple ornamental plant species.

Kungsparken is an old park (ca 150 years) in the very centre of the city. The residential areas surrounding the park are multi-storey buildings from the late 19th century. In the north, there is a canal built in the 17 th century that delimits the park. There are several busy traffic routes and paved walkways crossing the park. Veteran trees, e.g. oak, lime (Tilia cordata), beech (Fagus silvatica) and several introduced species such as horse chestnut (Aeculus hippocastanum), are predominant in the park. The ground is covered by large lawns with a few ornamental flower beds.

Wieselgrensplatsen is a residential area with three-storey buildings from the 1940s. There are some local roads across the area. Well managed lawns dominate the courtyards. There are also a few trees, e.g. crack willow (Salix fragilis) and maple (Acer sp.), and groups of ornamental plants.

Some parts of the visually dominant biodiversity were measured. Following previous studies (Fuller et al. 2007; Shwartz et al. 2014; Carrus et al. 2015) we focused on the vegetation as a major part of biodiversity being perceived by people. In addition, songbirds were monitored because they can have a great influence on perception of urban sites (Hedblom et al. 2014). We also included bumblebees because they are highly conspicous invertebrates that are noticed by the public (Bjerke and Østdahl 2004).

The vegetation in each site was investigated by counting trees, bushes and herbs in circular plots with a radius of $20 \mathrm{~m}$, $10 \mathrm{~m}$, and $0.28 \mathrm{~m}$, respectively (method used by Swedish national monitoring, see Ståhl et al. 2011). The species

Table 1 Biodiversity estimated in six urban sites across Gothenburg

\begin{tabular}{|c|c|c|c|c|c|c|}
\hline & Guldheden & Titteridamm & Sörhallsparken & Änggårdskolonin & Kungsparken & Wieselgrensplatsen \\
\hline Site & Urban wood-land & Suburban woodland & New park \& urban grove & Allotment area & Central old park & Residential area \\
\hline Biodiversity category & High & High & Medium & Medium & Low & Low \\
\hline Total area (ha) & 12.0 & 38.4 & 6.4 & 1.9 & 9.8 & 8.9 \\
\hline Trees (spp/ha) & $74.3 \pm 7.0$ & $43.8 \pm 4.0$ & $39.8 \pm 16.9$ & $39.8 \pm 8.0$ & $37.8 \pm 2.0$ & $8.0 \pm 8.0$ \\
\hline Bushes (spp/ha) & $90.2 \pm 2.6$ & $69.7 \pm 9.4$ & $21.9 \pm 12.7$ & $123.4 \pm 19.9$ & 0 & 0 \\
\hline Herbs $\left(\mathrm{spp} / \mathrm{m}^{2}\right)$ & $14.4 \pm 2.3$ & $9.5 \pm 2.3$ & $19.0 \pm 2.6$ & $10.2 \pm 5.5$ & $18.3 \pm 1.5$ & $20.3 \pm 2.3$ \\
\hline Songbirds (no spp) & 12 & 15 & 6 & 11 & 14 & 9 \\
\hline Songbirds (1/D) & 11.3 & 10.5 & 9.0 & 8.0 & 8.0 & 8.5 \\
\hline Bumblebees (no spp) & 3 & 5 & 4 & 4 & 3 & 2 \\
\hline Bumblebees (1/D) & 0 & 3.3 & 2.8 & 1.8 & 2.5 & 1.3 \\
\hline
\end{tabular}

The sites were combined into three categories: high, medium and low biodiversity (see text). Vegetation was measured as species density in sampling plots (mean number of species per area \pm s.e.). Songbirds and bumblebees were measured by point counts (number of species observed per site; diversity estimated by Simpson's index (1/D)) 
richness of trees, bushes and herbs was expressed as number of species per area (trees and bushes per ha, herbs per $\mathrm{m}^{2}$ ). The number of species was counted irrespective of their origin, i.e. both native and non-native plants were counted and included in the estimate of species richness. A stratified sampling design was used for the vegetation in our study sites. This was done to ensure that the habitat variation in each site was captured in the samples. The number of plots per site varied between 2 and 4 (trees and bushes) and 6 and 12 (herbs) depending on size of the site and the habitat heterogeneity. As can be seen in Table 1, the standard error was typically around $10 \%$ of the mean, indicating an acceptable precision of the measurement on each site (Southwood and Henderson 2000). But in Sörhallsparken and Wieselgrensplatsen, standard error was higher for trees and bushes due to high variation between sampling plots (lawns without trees vs groves with trees). This would not have been changed to any great extent by increasing the number of sampling plots because of the large differences in vegetation composition between sampling strata.

Our survey included two animal groups; species numbers and diversity (Simpson's index 1/D, see Magurran 2004) of songbirds and bumblebees in each site were estimated by standardized point counts. On each site, birds were counted at two points that were visited three times in April to June 2013. Bumblebees were monitored three times at three points in each site during July and August 2013.

The six sites were redefined into three categories of biodiversity: high, medium, and low. This categorization was done to increase the number of replies per category and was based on the totalled ranking of mean values for species density of trees, bushes, and herbs, and diversity of songbirds and bumblebees (Table 1).

\section{Measures in survey}

Aesthetic perception Participants were asked to estimate their aesthetic perceptions of the nearby urban greenery on a 7point scale, ranging from 1 (completely disagree) to 7 (completely agree). The measure comprised four statements: "Naturalistic"; "Rich in species"; "Lush"; and "Varied".

Greenery-related sound perception Participants were asked to estimate different types of urban greenery-related sounds on a 7-point scale, ranging from 1 (completely disagree) to 7 (completely agree). The measure comprised three statements: "Sounds of nature give me a stronger perception of the site"; "It is important for me to listen to the bird song in the area"; and "Sounds of nature are important for my perception of bird species in the area".

Importance of trees and plants for the perception of bird species Participants were asked to respond to two statements on a 7-point scale, ranging from 1 (completely disagree) to 7 (completely agree): "Trees are important to my perception of bird species in the area"; and "Plants are important to my perception of bird species in the area".

Urban-oriented person attitude This was measured on a 7point scale: 1 (completely disagree) to 7 (completely agree) related to the question: "Are you an urban-oriented person, finding pleasure in street life, shopping, and amusements of the city?"

Nature-oriented person attitude This was measured on a 7point scale: 1 (completely disagree) to 7 (completely agree) related to the question: "Are you a nature-oriented person, finding pleasure in the sea, woods, and nature?"

\section{Statistical design and analyses}

A non-equivalent comparison-group quasi-experimental design (McGuigan 1983) was used. Thus, compared with a "true experiment" (Liebert and Liebert 1995), the inferences drawn about the causal relationships between independent and dependent variables might be considered weaker.

Independent variables Three independent variables were included: 3 Biodiversity (high, medium, low) $\times 2$ Urbanoriented person (high, low); $\times 2$ Nature-oriented person (high, low). This means that the green space was redefined from six sites to three biodiversity categories of high, medium and low. Scales measuring the two attitudes of urban and nature oriented person were dichotomized into high vs. low conditions, respectively. In order to investigate contrasting positions (high vs. low) of an attitude, it is recommended to split a continuously scaled variable at the median (DeCoster et al. 2009), i.e. H-person vs. L-person. Thus, respondents lower than median were considered to be "low" and those higher than median were considered to be "high" on the respective independent variable of urban- (low vs. high) and nature-oriented (low vs. high) attitude. This was done in order to investigate urbannature-oriented attitude polarized by "high" vs. "low" individuals respectively (e.g., Knez 2005, 2013; Knez and Thorsson 2006). This does not, however, imply that urban- and natureoriented attitudes are orthogonal, meaning that a respondent cannot score "high" or "low" on both attitudes. People can indeed appreciate or not both the city and the nature. As shown in Table 2, most of the subjects (543) were not particularly fond of either the city or the nature. However, 165 respondents were shown to estimate themselves as high on both attitudes. It was also shown that 243 and 322 respondents estimated themselves as being high-nature-low-urban and high-urban-low-nature oriented persons respectively. 
Table 2 Number of respondents across high/ low urban-oriented and nature-oriented attitude

\begin{tabular}{cccc}
\hline \multicolumn{4}{c}{ Nature-oriented } \\
High & Low & Total \\
Urban-oriented & & \\
High & 165 & 322 & 487 \\
Low & 243 & 543 & 786 \\
Total & 408 & 865 & 1273 \\
\hline
\end{tabular}

Dependent variables Participants' aesthetic perception of urban green space, urban green-space-related sound perception and the importance of trees and plants for the perception of bird species in urban greenery were used as dependent variables.

Statistical analyses Multivariate analysis of variance (MANOVA) was used because the three dependent variables involved more than one scale/statement. The independent variables of Biodiversity, Urban-oriented person and Natureoriented person were treated as between-subject factors. The software IBM SPSS Statistics 22 was used for statistical computations.

\section{Results}

\section{Aesthetic perception}

MANOVA showed three main effects of Biodiversity, Natureoriented and Urban-oriented person, and an interaction effect of Biodiversity and Nature-oriented person. Only significant results are reported throughout the paper. The impact of Biodiversity (Wilks $\lambda=0.81, F(8,2300)=31.41, p<0.01$, $\left.\eta^{2}=0.10\right)$ was associated with all four statements of "naturalistic" $(p<0.01)$, "rich in species" $(p<0.01)$, "lush" $(p<0.01)$, and "varied" $(p<0.01)$. As can be seen in Fig. 2, the level of urban green-space aesthetics was perceived in a descending order from high, medium to low Biodiversity; thus, in accordance with the measured, "objective" subdivision of biodiversity.

The impact of Nature-oriented person (Wilks $\lambda=0.97$, $\left.F(4,1150)=8.16, p<0.01, \eta^{2}=0.03\right)$ was significant for all four statements of "naturalistic" $(p<0.01)$, "rich in species" $(p<0.01)$, "lush" $(p<0.01)$, and "varied" $(p<0.01)$. Highly Nature-oriented persons were shown to give higher scores to urban green space-related aesthetics than less Nature-oriented persons did (Fig. 3; HNature person vs. L-Nature person).

However, an interaction effect of Biodiversity and Nature-oriented person (Wilks $\lambda=0.97, F(8$, $\left.2300)=3.46, p<0.01, \eta^{2}=0.01\right)$ showed that the difference in urban greenery-related aesthetic perception between highly and less Nature-oriented persons was confined to the two high and medium Biodiversity conditions. In other words, there was no difference between highly and less Nature-oriented persons in perceiving urban greenery in low Biodiversity condition (Fig. 4). The percentages of respondents rated as highly Natureoriented persons living near high, medium and low Biodiversity sites were $35.5,31.0$ and $30.5 \%$, respectively.

The impact of Urban-oriented person (Wilks $\lambda=0.98$, $\left.F(4,1150)=6.19, p<0.01, \eta^{2}=0.02\right)$ was associated with all four statements of "naturalistic" $(p<0.01)$, "rich in species" $(p<0.01)$, "lush" $(p<0.01)$, and "varied" $(p<0.01)$. In line with the results above (Fig. 3), Highly Urban-oriented persons were shown to perceive more urban greenery-related aesthetics than less Urban-oriented persons did (Fig. 5).

\section{Sound perception}

MANOVA showed three main effects of Biodiversity, Nature-oriented and Urban-oriented person. The impact of Biodiversity (Wilks $\lambda=0.91, F(6,2422)=20.41$, $\left.p<0.01, \eta^{2}=0.05\right)$ was significant for all three statements of "Sounds of nature give me a stronger perception of the site" ( $p<0.01)$; "It is important for me to listen to the bird song in the area" $(p<0.01)$; and "Sounds of nature are important for my perception of bird species in the area" $(p<0.01)$. In a similar way to that shown for aesthetic perception (Fig. 2), the urban greenery-related sounds were perceived in a descending order from high, medium to low Biodiversity condition; thus, in accordance with the measured, "objective" subdivision of biodiversity (Fig. 6).

The impact of Nature-oriented person (Wilks $\lambda=0.93$, $\left.F(3,1211)=29.66, p<0.01, \eta^{2}=0.07\right)$ was also shown to be significant for all three statements of "Sounds of nature give me a stronger perception of the site" $(p<0.01)$; "It is important for me to listen to the bird song in the area" $(p<0.01)$; and "Sounds of nature are important for my perception of bird species in the area" $(p<0.01)$. Highly Nature-oriented persons were shown to value greeneryrelated sounds higher than less Nature-oriented persons did (see Fig. 7).

The impact of Urban-oriented person (Wilks $\lambda=0.99$, $\left.F(3,1211)=4.07, p<0.01, \eta^{2}=0.01\right)$ was associated only with the "Sounds of nature give me a stronger perception of the site" statement $(p<0.01)$; showing that highly Urban-oriented persons perceived the sounds of nature in urban greenery in a stronger way than less Urbanoriented persons did $($ mean $=5.14$, s.e. $=0.08 \mathrm{vs}$ mean $=4.89$, s.e. $=0.07)$. 
Fig. 2 Mean aesthetic perception of urban greenery (comprising four statements of naturalistic, rich in species, lush, and varied) as a function of Biodiversity (high, medium, low)

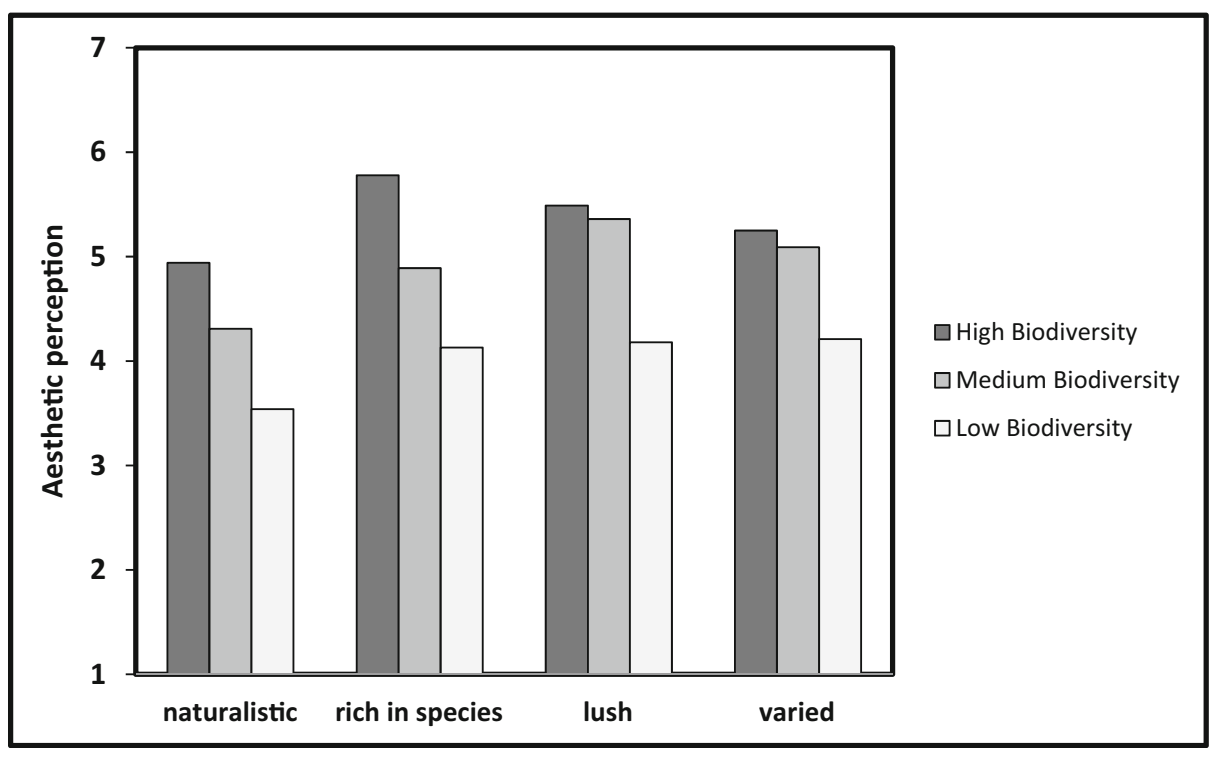

\section{Importance of trees and plants for perception of bird species}

MANOVA showed no multivariate effect of Biodiversity, but a univariate effect of Biodiversity on both statements that "Trees are important to my perception of bird species in the area" $(p=0.05)$; and "Plants are important to my perception of bird species in the area" $(p=0.03)$. As can be seen in Fig. 8 , the importance of trees and plants for perception of bird species in urban greenery was shown to differ only between high and medium/low Biodiversity conditions.

The impact of Nature-oriented person (Wilks $\lambda=0.94, F(2$, 1212) $\left.=36.59, p<0.01, \eta^{2}=0.06\right)$ was significant for both statements that "Trees are important to my perception of bird species in the area" $(p<0.01)$; and "Plants are important to my perception of bird species in the area" $(p<0.01)$. Highly Nature-oriented persons were shown to attribute greater importance to trees and plants for their perception of bird species in urban greenery than less Nature-oriented persons did (Fig. 9).

\section{Discussion}

We have shown that participants" "subjective" aesthetic and sound-related perceptions of urban green space were in line with the "objectively" measured subdivisions of high, medium and low biodiversity. Their estimations of the importance of trees and plants for perception of bird species in urban greenery followed a similar pattern differing only between
Fig. 3 Mean aesthetic perception of urban greenery (comprising four statements of naturalistic, rich in species, lush, and varied) as a function of Nature-oriented person attitude (high: H-Nature person, low: L-Nature person)

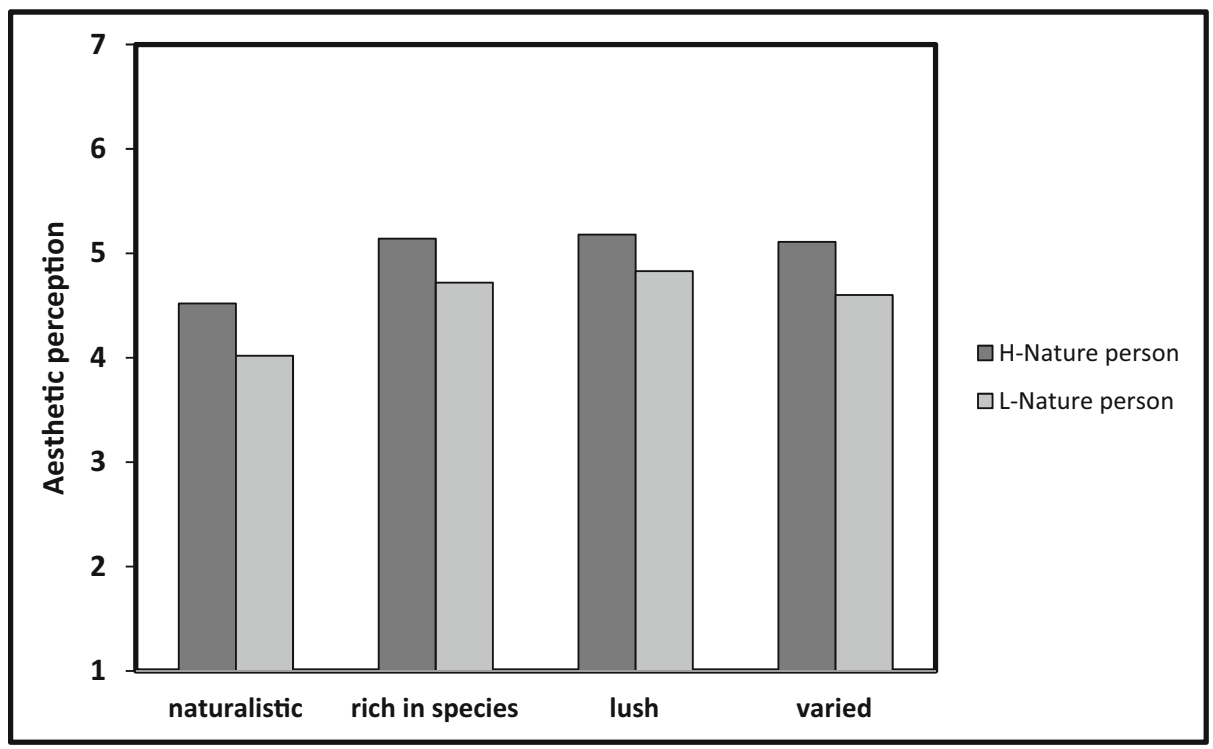


Fig. 4 Mean aesthetic perception of urban greenery (across four statements of naturalistic, rich in species, lush, and varied) as a function of Biodiversity (high, medium, low) and Natureoriented person attitude (high, low)

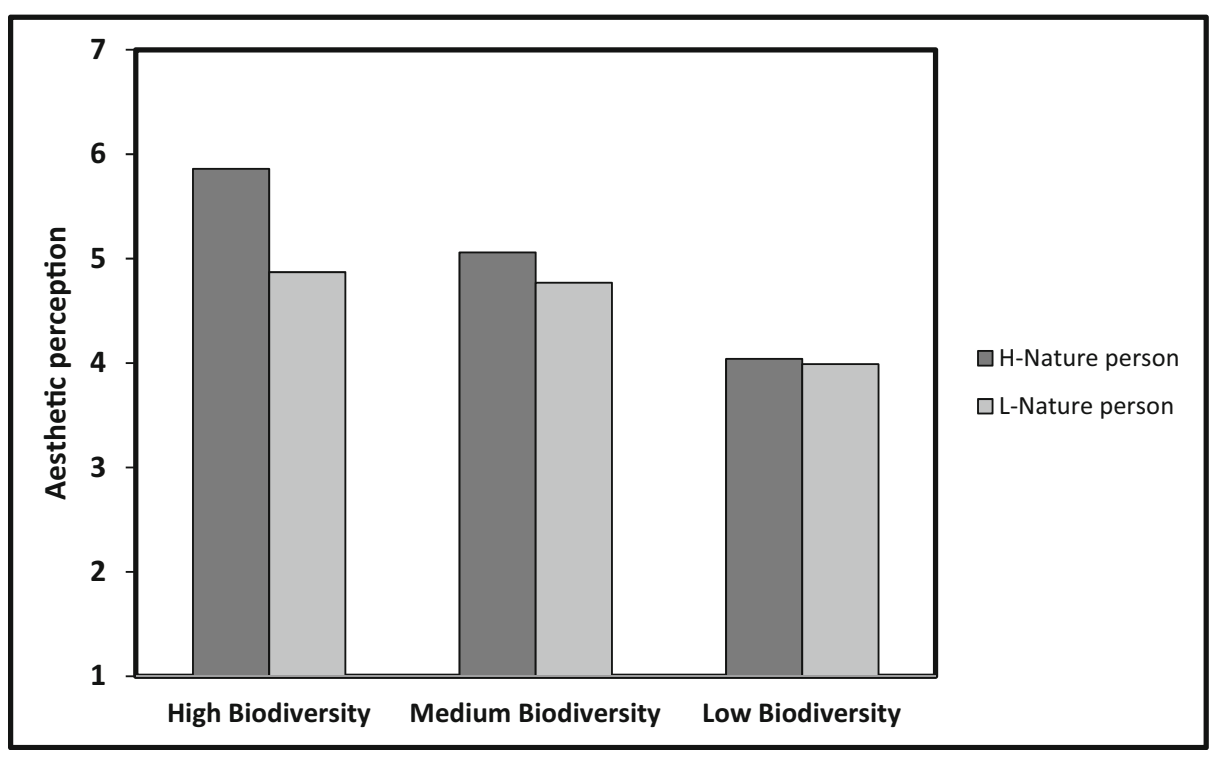

high and medium/low biodiversity conditions. This suggests that aesthetic experiences of green space in high biodiversity spots, on a relative scale, were more valued than low diversity spots. In other words, perceived positive values of urban greenery were highest where biodiversity was highest.

Our findings support the idea that high levels of actual biodiversity (measured in the field) contribute to positive aesthetic perceptions of green spaces. However, we are unable to conclude that biodiversity caused the differences in perception since there might be another factor, related to the level of biodiversity, which is the actual cause. On the other hand, one of the statements in the survey ("rich in species") explicitly pointed out that the respondents should focus on the biodiversity level. This suggests that the respondents presumably had species richness in mind in their assessment of each site. Some of the previous studies have indicated that urban inhabitants might prefer high species richness perceived via visual (e.g. Fuller et al. 2007; Carrus et al. 2015) or auditory stimuli (Hedblom et al. 2014).

The environment-related attitude was shown to influence participants' perception associated with the statements: "naturalistic", "rich in species" "lush" and "varied" (Fig. 2) but the difference in aesthetic perception did not occur at the low biodiversity sites (Fig. 3). This suggests that the aesthetic perception of city dwellers with highly nature-oriented attitudes has a wider span depending on the actual level of biodiversity than that of people with low nature orientation. However, highly urban-oriented attitude vs less urban-oriented attitude had a similar effect (Fig. 4) to highly nature-oriented attitude vs less nature-oriented attitude, suggesting that "high" environment-related attitude per se influences perception. Moreover, there was a higher proportion of highly nature-
Fig. 5 Mean aesthetic perception of urban greenery (comprising four statements of naturalistic, rich in species, lush, and varied) as a function of Urban-oriented person attitude (high: H-Urban person, low: L-Urban person)

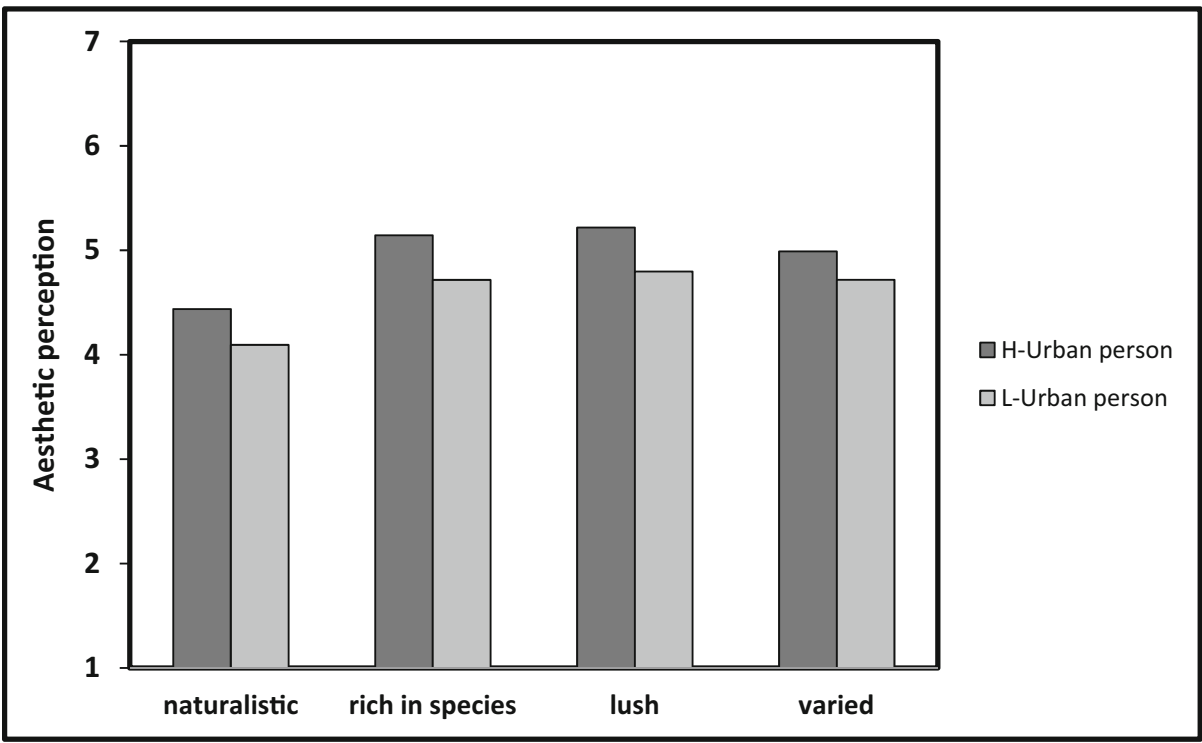


Fig. 6 Mean sound perception of urban greenery (comprising three statements of "Sounds of nature give me a stronger perception of the site"; "It is important for me to listen to the bird song in the area"; and "Sounds of nature are important for my perception of bird species in the area") as a function of Biodiversity (high, medium, low)

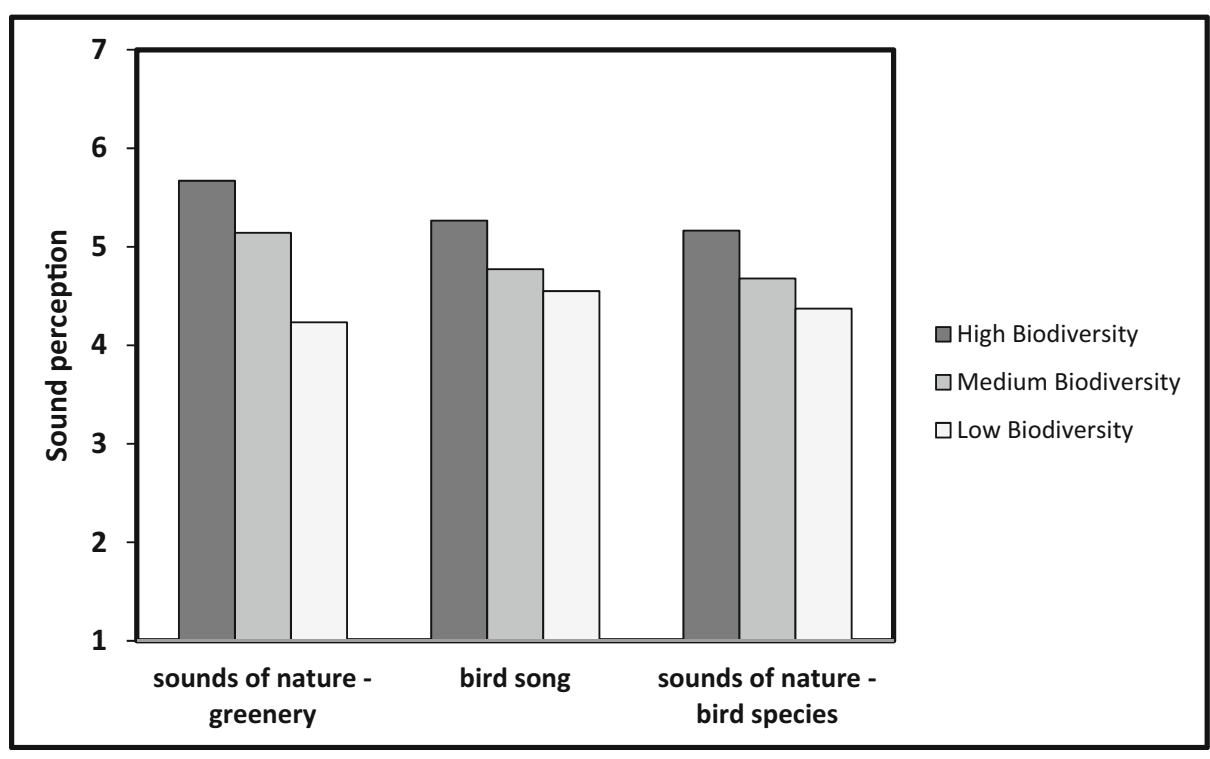

oriented person living near the sites with high biodiversity. This might suggest an association between nature-oriented attitude and the choice of a living-place. But the difference in perception between medium and low biodiversity sites was not explained by such a mechanism because the proportion of highly nature-oriented persons was similar in these sites.

Previous studies have reported mixed results regarding the importance of actual biodiversity and perception of aesthetics or well-being by green-space visitors. In earlier studies, the participants have often been on an occasional visit to a public park or similar type of green space (e.g. Fuller et al. 2007; Shwartz et al. 2014; Carrus et al. 2015). We found that a high level of measured biodiversity and a perceived high value of the greenery and sounds followed each other in areas close to where participants lived. This suggests that most of the respondents were familiar with the green space they rated.
Repeated and regular visits to a green space have previously been shown to increase well-being in a self-regulating way (Korpela 1992; Knez 2006). The attachment to well-known urban green spaces may partly explain our findings. The implication is that the longer the green space has been used by city inhabitants the more valuable it will become to people living nearby. This is in line with some previous research indicating that "extending one's stay at a place incorporates that place as a part of oneself” (Knez 2014, p. 173; Knez 2005).

We were not able to sample all kinds of biodiversity in the different green spaces. The major parts of the vegetation, i.e. trees, bushes and herbs, were included in our sampling program. We assumed that a large part of green space perception is associated with the experience of the greenery, i.e. the plants that we sampled. Previous studies support our assumption and
Fig. 7 Mean sound perception of urban greenery (comprising three statements of "Sounds of nature give me a stronger perception of the site"; "It is important for me to listen to the bird song in the area"; and "Sounds of nature are important for my perception of bird species in the area") as a function of Nature-oriented person attitude (high, low)

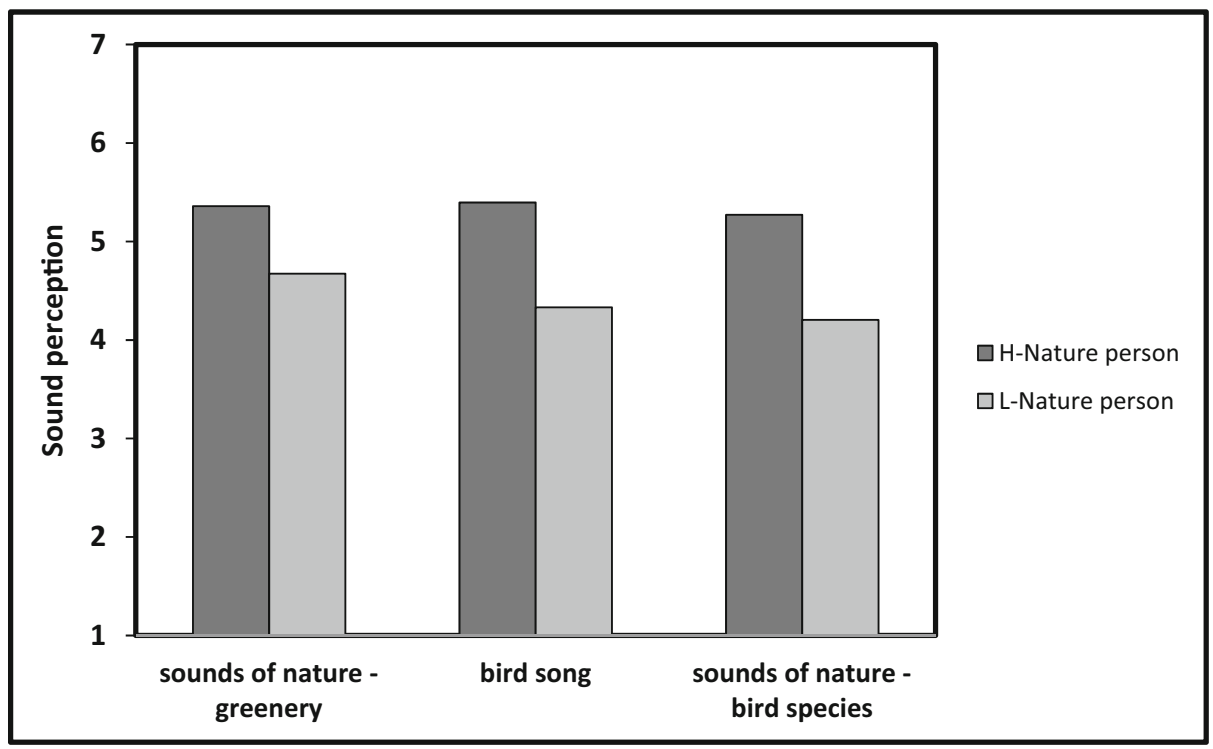


Fig. 8 Mean importance of trees and plants for perception of bird species (comprising two statements of "Trees are important to my perception of bird species in the area"; and "Plants are important to my perception of bird species in the area") as a function of Biodiversity (high, medium, low)

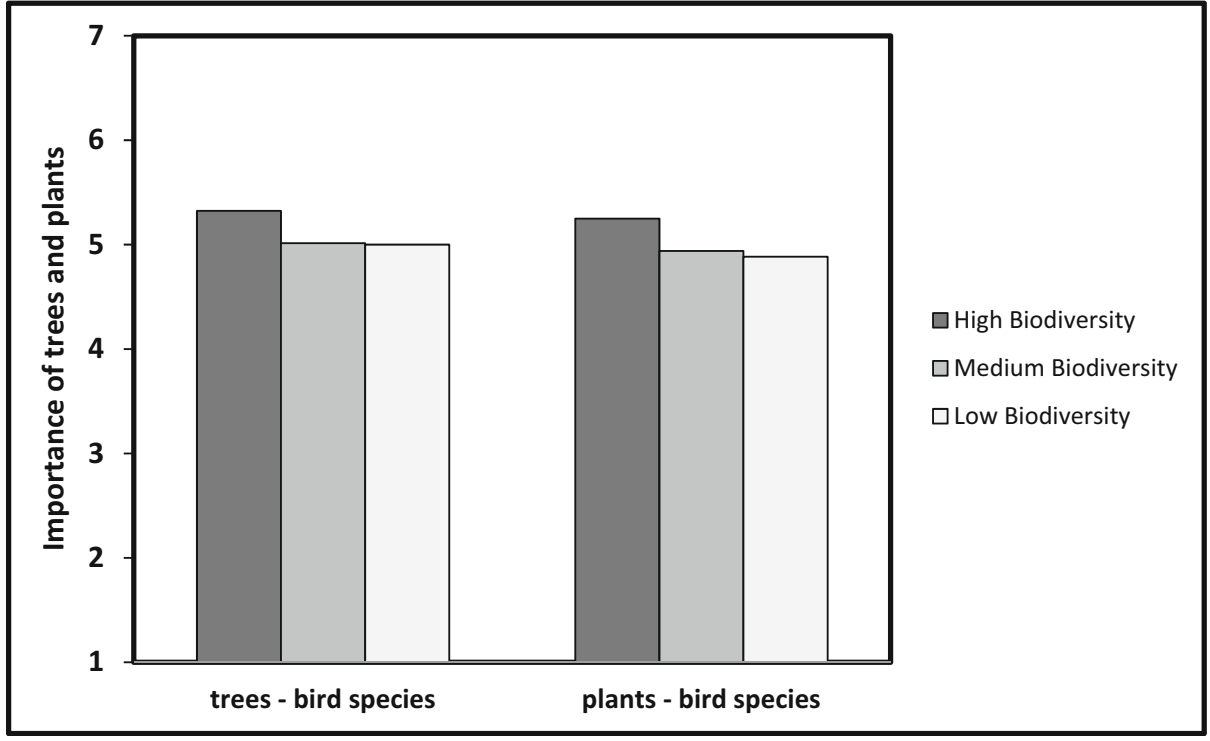

the perception of urban green space has often focused on conspicuous plants (Fuller et al. 2007; Dallimer et al. 2012; Shwartz et al. 2014; Carrus et al. 2015; Shanahan et al. 2015). Moreover, vegetation cover was positively related to personal well-being in a study comprising 9 Australian towns and cities (Luck et al. 2011). Future studies on perception of urban vegetation should focus on possible positive covariation between species richness and vegetation cover because it is not well known whether people differentiate between them.

We also included bird counts in our categorization of biodiversity. However, we focused on songbirds that are relevant to our survey. Previous investigations in urban green space in England have indicated that bird species richness can be positively associated with "continuity with past and attachment" (Fuller et al. 2007). Luck et al. (2011) found bird abundance to be related to personal well-being but only weakly. In our sampling we also included bumblebees because they are highly conspicuous arthropods and their abundance in cities is often positively associated with an abundance of flowering plants (Matteson and Langellotto 2010; Gunnarsson and Federsel 2014).

Our data regarding sound perception showed that actual biodiversity enhanced the experience (Fig. 5). The sounds of nature gave respondents an even stronger perception of the site when biodiversity was high compared to sites with medium biodiversity, which in turn gave stronger perception than low biodiversity sites. And it was more important to listen to birdsong, and sounds of nature were more important for perception of birds in sites with high biodiversity compared to sites with lower diversity. Just as with aesthetics, persons with a highly nature-oriented attitude had a higher, or stronger, perception of various sounds of nature (Fig. 6). The
Fig. 9 Mean importance of trees and plants for perception of bird species (comprising two statements of "Trees are important to my perception of bird species in the area"; and "Plants are important to my perception of bird species in the area") as a function of Nature-oriented person attitude (high, low)

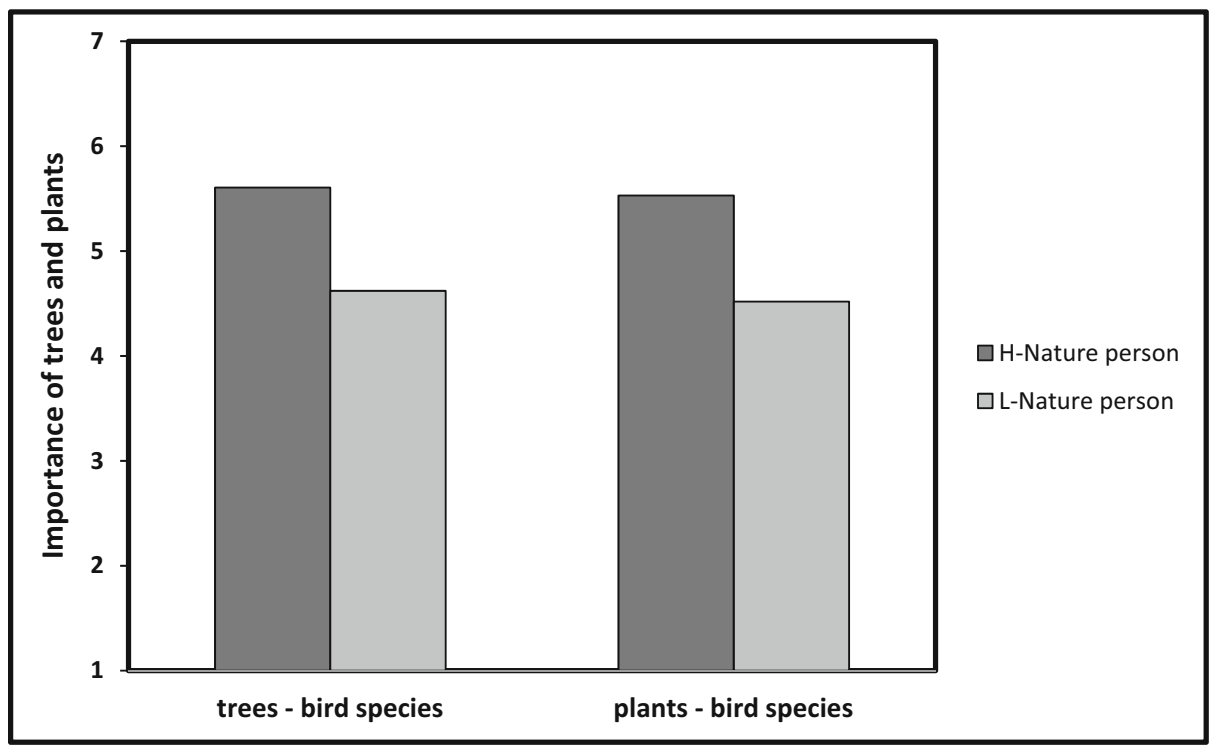


importance of natural sounds, e.g. birdsong, in cities and the effects on humans are largely unknown. Few studies have examined the effects of acoustic encounters with songbirds on urban inhabitants but there are indications that song by at least some species can increase well-being (Hedblom et al. in press). Perhaps this explains why songbirds are among the most appreciated wild life in cities (Bjerke and Østdahl 2004).

Sounds in cities are often related to man-made activities that are negatively perceived as noise (e.g. Viollon et al. 2002). But in green spaces there are sometimes various natural sounds that are perceived as pleasant, e.g. birdsong (e.g. Carles et al. 1999; Viollon et al. 2002). Hedblom et al. (2014) showed that urban settings combined with birdsong were more highly valued than the settings alone. We showed here that the attitude towards nature influenced how birdsong and other sounds of nature were perceived (Fig. 6). Moreover, there was an influence by trees and other plants on perception of bird species in green space. This was affected by both the level of biodiversity (high vs medium/low; Fig. 7) and the attitude of nature-oriented person (Fig. 8). A possible explanation for these findings is that persons with a highly natureoriented attitude are more likely to link different parts of biodiversity in their perception of urban green space.

Highly compared to less nature-oriented persons were shown to perceive more urban greenery-related aesthetics, more greenery-related sounds, and greater importance of trees and plants for their perception of bird species in urban greenery. Highly compared to less urban-oriented persons did the same, but only regarding urban greenery-related aesthetics and sounds of nature. This is in line with previous research showing effects of individualistic environment-related attitudes on persons' perceptions of urban places (Knez and Thorsson 2006, 2008), meaning that respondents' knowledge and expectations of urban sites stored in memory (Brewer and Treyens 1981) may indeed influence perception of physical places (Knez 2006, 2014). Recent research in Brisbane, Australia, has shown that park visitors with stronger nature orientation traveled further and made longer visits than park users with a less pronounced nature orientation (Lin et al. 2014). Moreover, park visitors with greater nature orientation tended to go to urban parks with higher levels of tree cover and remnant native vegetation and thus they were prepared to travel to such parks instead of using nearby parks (Shanahan et al. 2015). Individual differences in perception of green space should thus be addressed when urban planners design city parks. The involvement of the public in the planning process at the local level might facilitate a more "adaptive" process resulting in more variation of urban green space. This could develop into a "win-win" situation with more variation of biodiversity and more satisfied green space users at the citylevel scale.

The idea that perceived diversity is important for a positive experience of landscape is well supported in previous studies (see review by Ode et al. 2010). Moreover, the relationship between preference and aspects of well-being is supported by several studies (e.g. Purcell et al. 2001; Staats et al. 2003; Tenngart Ivarsson and Hagerhall 2008). However, when linking perception of diversity to landscape preference, there is a need to include aspects such as hierarchy, grouping and repetition in order to fully explain the relationship between experienced diversity and landscape preference. For instance, preference for a green space with the same amount and type of species diversity is affected by the presence of signs of order and care (Nassauer 1995, 1997) and is thereby likely to influence the sense of well-being associated with the area.

Our study of the effects of biodiversity and environmentrelated attitude on perception of urban green space does not point out which of the factors that is the most important one. Such a conclusion would be difficult to make because the factors are interacting and affecting people's perceptions in site-specific ways. However, our findings are in line with previous research indicating that well-known places can be "part of oneself" (Knez 2005, 2014). This might suggest that environment-related attitude plays a crucial role in order to develop such an attachment to a specific urban green space.

Taken together, our findings support the idea that a high level of measured, "objective", biodiversity has a positive influence on nearby city inhabitants' perception of greeneryrelated aesthetics in Gothenburg. Furthermore, we conclude that the attitude to nature and urban orientation plays a major role in positive perception of green space and nature sounds. But a high level of environment-related attitude per se seems to be more important than the nature or urban orientation. Urban planning thus needs to take into account that biodiversity matters and in order to provide all inhabitants with greenery experiences, green spaces need to be species rich, lush, varied and rich in natural sounds.

Acknowledgments We thank two anonymous reviewers for valuable comments on the paper. This study was supported by the Swedish Research Council for Environment, Agricultural Sciences and Spatial Planning (FORMAS), Mistra Urban Futures and the Swedish Transport Administration within the project "Valuation of ecosystem services provided by urban greenery".

\section{Compliance with ethical standards}

Conflict of interest The authors declare that they have no conflict of interest.

Open Access This article is distributed under the terms of the Creative Commons Attribution 4.0 International License (http:// creativecommons.org/licenses/by/4.0/), which permits unrestricted use, distribution, and reproduction in any medium, provided you give appropriate credit to the original author(s) and the source, provide a link to the Creative Commons license, and indicate if changes were made. 


\section{References}

Annerstedt M, Jönsson P, Wallergård M, Johansson G, Grahn P, Hansen ÅM, Währborg P (2013) Inducing physiological stress recovery with sounds of nature in a virtual reality forest — results from a pilot study. Physiol Behav 118:240-250

Bjerke T, Østdahl T (2004) Animal-related attitudes and activities in an urban population. Anthrozoös 17:109-129

Björk EA (1986) Laboratory Annoyance and skin-conductance responses to some natural sounds. J Sound Vib 109:339-345

Brewer WF, Treyens JC (1981) Role of schemata in memory for places. Cogn Psychol 13:207-230

Carles JL, Barrio IL, de Lucio JV (1999) Sound influence on landscape values. Landscape Urban Plan 43:191-200

Carrus G, Scopelliti M, Lafortezza R, Colangelo G, Ferrini F, Salbitano F, Agrimi M, Portoghesi L, Semenzato P, Sanesi G (2015) Go greener, feel better? the positive effects of biodiversity on the well-being of individuals visiting urban and peri-urban green areas. Landscape Urban Plan 134:221-228

Clark NE, Lovell R, Wheeler BW, Higgins SL, Depledge MH, Norris K (2014) Biodiversity, cultural pathways, and human health: a framework. Trends Ecol Evol 29:198-204

Dallimer M, Irvine KN, Skinner AMJ, Davies ZG, Rouquette JR, Maltby LL, Warren PH, Armsworth PR, Gaston KJ (2012) Biodiversity and the feel-good factor: understanding associations between selfreported human wellbeing and species richness. Bioscience 62:47-55

DeCoster J, Iselin A-MR, Galluci M (2009) A conceptual and empirical examination of justifications for dichotomization. Psychol Methods 4:349-366

Eagly AH, Chaiken S (1993) The psychology of attitudes. Harcourt Brace College Publishers, New York

Fuller RA, Irvine KN, Devine-Wright P, Warren PH, Gaston KJ (2007) Psychological benefits of greenspace increase with biodiversity. Biol Lett 3:390-394

Gunnarsson B, Federsel LM (2014) Bumblebees in the city: abundance, species richness and diversity in two urban habitats. J Insect Conserv 18:1185-1191

Hartig T, Staats H (2006) The need for psychological restoration as a determinant of environmental preferences. J Environ Psychol 26: 215-226

Hartig T, Mitchell R, de Vries S, Frumkin H (2014) Nature and health. Annu Rev Public Health 35:207-228

Hedblom M, Heyman E, Antonsson H, Gunnarsson B (2014) Bird song diversity influences young people's appreciation of urban landscapes. Urban Forest Urban Greening 13:469-474

Hedblom M, Knez I, Gunnarsson B (in press) Bird diversity and human well-being in cities. In "Ecology and Conservation of Birds in Urban Environments" Eds Murgui E, Hedblom M, pp x-x, Springer Verlag, Berlin

Hirsch JB, Peterson JB (2009) Extraversion, neuroticism, and the prisoner's dilemma. Personal Individ Differ 46:254-256

Irvine KN, Devine-Wright P, Payne SR, Fuller RA, Painter B, Gaston KJ (2009) Green space, soundscape and urban sustainability: an interdisciplinary, empirical study. Local Environ 14:155-172

Johansson M, Gyllin M, Witzell J, Küller M (2014) Does biological quality matter? direct and reflected appraisal of biodiversity in temperate deciduous broad-leaf forest. Urban Forest Urban Greening $13: 28-37$

Knez I (2005) Attachment and identity as related to a place and its perceived climate. J Environ Psychol 25:207-218

Knez I (2006) Autobiographical memories for places. Memory 14:359-377

Knez I (2013) How concerned, afraid and hopeful are we? effects of egoism and altruism on climate change related issues. Psychology $10: 744-752$
Knez I (2014) Place and the self: an autobiographical memory synthesis. Philos Psychol 2:164-192

Knez I, Thorsson S (2006) Influences of culture and environmental attitude on thermal, emotional and perceptual evaluations of a square. Int J Biometeorol 50:258-268

Knez I, Thorsson S (2008) Thermal, emotional and perceptual evaluations of a park: cross-cultural and environmental attitude comparisons. Build Environ 43:1483-1490

Knez I, Thorsson S, Eliasson I, Lindberg F (2009) Psychological mechanisms in outdoor place and weather assessment: towards a conceptual model. Int J Biometeorol 53:101-111

Knez I, Thorsson S, Eliasson I (2013) Climate change: concerns, beliefs, and emotions in residents, experts, decision makers, tourists, and tourist industry. Am J Climate Change 2:254-269

Korpela KM (1992) Adolescents' favorite places and environmental selfregulation. J Environ Psychol 12:249-258

Liebert RM, Liebert LL (1995) Science and behavior: an introduction to methods of psychological research. Prentice Hall, New York

Lin BB, Fuller RA, Bush R, Gaston KJ, Shanahan DF (2014) Opportunity or orientation? who uses urban parks and why. PLoS ONE 9(1):e87422

Lindemann-Matthies P, Junge X, Matthies D (2010) The influence of plant diversity on people's perception and aesthetic appreciation of grassland vegetation. Biol Conserv 143:195-202

Luck GW, Davidson P, Boxall D, Smallbone L (2011) Relations between urban bird and plant communities and human well-being and connection to nature. Conserv Biol 25:816-826

Magurran A (2004) Measuring biological diversity, 2nd edn. Blackwell, Oxford

Matteson KC, Langellotto GA (2010) Determinates of inner city butterfly and bee species richness. Urban Ecosyst 13:333-347

McGuigan FJ (1983) Experimental psychology: methods of research. Prentice Hall, New Jersey

McKinney ML (2006) Urbanization as a major cause of biotic homogenization. Biol Conserv 127:247-260

MEA (2005) Millennium ecosystem assessment. Island Press, Washington DC

Milfont TL, Sibley CG (2012) The big five personality traits and environmental engagement: associations at the individual and societal level. J Environ Psychol 32:187-195

Nassauer JI (1995) Messy ecosystems, orderly frames. Landsc J 14:161-170

Nassauer JI (1997) Placing nature: culture and landscape ecology. Island Press, Washington, DC

Nisbet EKL, Zelenski JM, Murphy SA (2009) The nature relatedness scale: linking individuals'connection with nature to environmental concern and behaviour. Environ Behav 41:715-740

Ode Å, Hagerhall CM, Sang N (2010) Analysing visual landscape complexity: theory and application. Landsc Res 35:111-131

Perelman P, Breuste J, Madanes N, Gropper C, Melignani E, Faggi A (2013) Use of visitors' perception in urban reserves in the Buenos Aires metropolis. Urban Ecosyst 16:841-851

Pett TJ, Shwartz A, Irvine KN, Dallimer M, Davies ZG (2016) Unpacking the people-biodiversity paradox: a conceptual framework. Bioscience. doi:10.1093/biosci/biw036

Pettus AM, Giles MB (1987) Personality characteristics and environmental attitudes. Popul Environ 9:127-137

Purcell T, Peron E, Berto R (2001) Why do preferences differ between scene types? Environ Behav 33:93-106

Ratcliffe E, Gatersleben B, Sowden PT (2013) Bird sounds and their contribution to perceived attention restoration and stress recovery. J Environ Psychol 36:221-228

Seto KC, Güneralp B, Hutyra LR (2012) Global forecasts of urban expansion to 2030 and direct impacts on biodiversity and carbon pools. Proc Natl Acad Sci U S A 109:16083-16088 
Shanahan DF, Lin BB, Gaston KJ, Bush R, Fuller RA (2015) What is the role of trees and remnant vegetation in attracting people to urban parks? Landsc Ecol 30:153-165

Shwartz A, Turbé A, Simon L, Julliard R (2014) Enhancing biodiversity and its influence on city-dwellers: an experiment. Biol Conserv 171: $82-90$

Southwood TRE, Henderson PA (2000) Ecological methods, 3rd edn. Blackwell, Oxford

Staats H, Kieviet A, Hartig T (2003) Where to recover from attentional fatigue: an expectancy-value analysis of environmental preference. J Environ Psychol 23:147-157

Ståhl G, Allard A, Esseen P-A, Glimskär A, Ringvall A, Svensson J, Sundquist S, Christensen P, Gallegos Torell $\AA$, Högström M, Lagerqvist K, Marklund L, Nilsson B, Inghe O (2011) National Inventory of Landscapes in Sweden (NILS) - scope, design, and experiences from establishing a multiscale biodiversity monitoring system. Environ Monit Assess 173:579595
Standish RJ, Hobbs RJ, Miller JR (2012) Improving city life: options for ecological restoration in urban landscapes and how these might influence interactions between people and nature. Landsc Ecol 28: $1213-1221$

Statistics Sweden (2016) Population in the country, counties and municipalities on 31/12/2014 and population change in 2014. http://www. scb.se/en_/Finding-statistics/statistics-by-subjectarea/Population/Population-composition/Population-statistics/\#c li_26051. Accessed 17 May 2016

Tenngart Ivarsson C, Hagerhall CM (2008) The perceived restorativeness of gardens: assessing the restorativeness of mixed built and natural scene type. Urban Forest Urban Greening 7:107-118

Tzoulas K, Korpela K, Venn S, Yli-Pelkonen V, Kazmierczak A, Niemelä J, James P (2007) Promoting ecosystem and human health in urban areas using green infrastructure: a literature review. Landscape Urban Plan 81:167-178

Viollon S, Lavandier C, Drake C (2002) Influence of visual setting on sound ratings in an urban environment. Appl Acoust 63:493-511 